\title{
Theoretical Aspects of Triacylglycerin Positional Isomer Separation on Reverse Phase High Performance Liquid Chromatography
}

\author{
Tsugihiko Hirano ${ }^{1}$, Keiichi Yokochi ${ }^{2}$ and Koretaro Takahashi ${ }^{3 *}$ \\ 1 J-DEVICES CORPORATION, 145 Aza-Nakajima, Nanae-cho Kameda-gun, Hokkaido 041-1196, JAPAN \\ ${ }^{2}$ Presently, Maruha Nichiro Corporation, Toyosu Front, 3-2-20 Toyosu, Kotoh-ku Tokyo 135-8606, JAPAN \\ ${ }^{3}$ Faculty of Fisheries Sciences, Hokkaido University, 3-1-1 Minato-cho, Hakodate 041-8611, JAPAN
}

\begin{abstract}
The purpose of the present study is to bear our hypothesis and to make a profound discussion on the theoretical aspects of triacylglycerin (TG) positional isomer separation on reverse phase high performance liquid chromatography (HPLC). Authentic triacid TG positional isomers and authentic diacid TG positional isomers were injected to a monomeric and polymeric HPLC. Relationship between TG molecular structure and those elution profiles were carefully analyzed. In polymeric column, thickness of the ODS chain is high compared to monomeric column. And for this reason, clearances between the ODS stationary phase chains are considered to be very limited compared to those of monomeric column, thus limiting the TG molecule transformations and rotations to only a "longest stem direction" which gives the smallest resistance in passing through the ODS chains. The longest stem direction of the TG molecule was considered to be the crucial factor for the interaction between the stationary phase. And under this condition, interference occurring between the fatty acid moieties must be the main contributing factor for positional isomer separation in polymeric column. These aspects were considered to explain why they are not consistent with the addition theorem of A.J.P. Martin in partition chromatography.
\end{abstract}

Key words: triacylglycerin, monomeric, polymeric, positional isomer, chemical potential

\section{INTRODUCTION}

Thanks to the development of resolution on high performance liquid chromatography (HPLC), not only the fatty acid combination of triacylglycerin (TG) molecular species analysis but also the TG positional isomer analysis have become possible to some extent ${ }^{1,2}$. This is the result of the development on polymeric reverse phase column which has a high density modified carbon chains as stationary phase at least in part making it possible to discriminate positional isomers.

The theoretical aspects of elution order in TG molecular species can be depicted as follows rest on the addition theorem of A.J.P. Martin ${ }^{3)}$.

$$
\begin{aligned}
\Delta \mu \mathrm{TG}= & \Delta \mu_{1}+\Delta \mu_{2}+\Delta \mu_{3}-\left\{p\left(\Delta \mu_{1}, \Delta \mu_{2}\right)+p\left(\Delta \mu_{2}, \Delta \mu_{3}\right)\right. \\
& \left.+\mathrm{q}\left(\Delta \mu_{1}, \Delta \mu_{3}\right)\right\}
\end{aligned}
$$

where $\Delta \mu_{1}, \Delta \mu_{2}, \Delta \mu_{3}$ designate chemical potentials (i.e. free energy of a solute to transfer from stationary phase to mobile phase) of the individual TG acyl moieties FA1, FA2, FA3 on reverse phase HPLC. $p$ designates interference factors between $s n-1$ and $s n-2$ moieties, and $s n-2$ and $s n-3$ moieties, and q designates interference factors between $s n-1$ and $s n-3$ moieties that impairs the interaction between the TG molecule and stationary phase.

If we can ignore $\mathrm{p}$ and $\mathrm{q}$ factors, the partition chromatographic addition theorem proposed by A.J.P. Martin ${ }^{3)}$ should hold. We speculated that in monomeric reverse phase HPLC, the addition theorem of A.J.P. Martin ${ }^{3)}$ should hold while in polymeric reverse phase HPLC, q factors must be effective because it has a high density modified carbon chains as stationary phase.

The purpose of the present study is to bear out this hypothesis and to make a profound discussion on the theoretical aspects of TG positional isomer separation on reverse phase HPLC.

\footnotetext{
*Correspondence to: Koretaro Takahashi, Faculty of Fisheries Sciences, Hokkaido University, 3-1-1 Minato-cho, Hakodate 041-8611, JAPAN

E-mail: kore@fish.hokudai.ac.jp

Present address: Kitami Institute of Technology, 165 Koen-cho Kitami, Hokkaido 090-8507, JAPAN

Accepted December 26, 2016 (received for review December 20, 2016)
}

Journal of Oleo Science ISSN 1345-8957 print / ISSN 1347-3352 online

http://www.jstage.jst.go.jp/browse/jos/ http://mc.manusriptcentral.com/jjocs 


\section{T. Hirano, K. Yokochi and K. Takahashi}

\section{EXPERIMENTAL PROCEDURES}

\subsection{Materials}

The triacid type $s n-1$ palmitoyl, $s n-2$ acethyl, $s n-3$ lauroyl triacylglycerin $\left(\mathrm{C}_{16} \mathrm{C}_{2} \mathrm{C}_{12}\right)$, the $s n-1$ palmitoyl, $s n-2$ lauroyl, sn-3 acetyl triacylglycerin $\left(\mathrm{C}_{16} \mathrm{C}_{12} \mathrm{C}_{2}\right)$, the $s n-1$ lauroyl, sn-2 palmitoyl, sn-3 acetyl triacylglycerin $\left(\mathrm{C}_{12} \mathrm{C}_{16} \mathrm{C}_{2}\right)$, the $s n$-1 palmitoyl, sn-2 octanoyl, sn-3 lauroyl triacylglycerin $\left(\mathrm{C}_{16} \mathrm{C}_{8} \mathrm{C}_{12}\right)$, the $s n$-1 palmitoyl, sn-2 lauroyl, $s n-3$ octanoyl triacylglycerin $\left(\mathrm{C}_{16} \mathrm{C}_{12} \mathrm{C}_{8}\right)$, the sn-1 lauroyl, $s n$-2 palmitoyl, sn-3 octanoyl triacylglycerin $\left(\mathrm{C}_{12} \mathrm{C}_{16} \mathrm{C}_{8}\right)$, and the diacid type $s n-1,3$ lauroyl, $s n-2$ palmitoyl triacylglycerine $\left(\mathrm{C}_{12} \mathrm{C}_{16} \mathrm{C}_{12}\right)$, the $s n-1,2$ lauroyl, sn-3 palmitoyl triacylglycerine $\left(\mathrm{C}_{12} \mathrm{C}_{12} \mathrm{C}_{16}\right)$, the $s n$-1, 3 palmitoyl, sn-2 lauroyl triacylglycerine $\left(\mathrm{C}_{16} \mathrm{C}_{12} \mathrm{C}_{16}\right)$, the $s n-1,2$ palmitoyl, sn-3 lauloyl triacylglycerine $\left(\mathrm{C}_{16} \mathrm{C}_{16} \mathrm{C}_{12}\right)$, sn-1, 3 lauroyl, sn-2 caproyl triacylglycerine $\left(\mathrm{C}_{12} \mathrm{C}_{6} \mathrm{C}_{12}\right)$, the $s n-1,2$ lauroyl, sn-3 caproyl triacylglycerine $\left(\mathrm{C}_{12} \mathrm{C}_{12} \mathrm{C}_{6}\right)$, the $s n-1,3$ palmitoyl, $s n-2$ butyroyl triacylglycerine $\left(\mathrm{C}_{16} \mathrm{C}_{4} \mathrm{C}_{16}\right)$, the $s n-1,2$ palmitoyl, $s n$-3 butyroyl triacylglycerine $\left(\mathrm{C}_{16} \mathrm{C}_{16} \mathrm{C}_{4}\right)$, the $s n-1,3$ palmitoyl, sn-2 octanoyl triacylglycerine $\left(\mathrm{C}_{16} \mathrm{C}_{8} \mathrm{C}_{16}\right)$, the $s n-1,2$ palmitoyl, sn-3 octanoyl triacylglycerine $\left(\mathrm{C}_{16} \mathrm{C}_{16} \mathrm{C}_{4}\right)$ were all generous gifts from TSUKISHIMA FOODS INDUSTRY CO., LTD. All chromatographic solvents were used without further purification.

\subsection{Reverse phase HPLC system.}

Pump: LC-10AT vp (Shimadzu Corporation, Kyoto), RI Detector: RID-10A (Shimadzu Corporation, Kyoto), Columns: Inertsil ODS-SP, $5 \mu \mathrm{m}, 4.6 \times 250 \mathrm{~mm}$, End capped, Monomeric (GL Sciences Inc., Tokyo), in tandem, or Inertsil ODS-P, $3 \mu \mathrm{m}, 4.6 \times 250 \mathrm{~mm}$, Non end capped, Polymeric (GL Sciences Inc., Tokyo), in tandem. Mobil phase: Acetonitrile/2-Propanol $/ n$-Hexane $=6: 4: 1(\mathrm{v} / \mathrm{v} / \mathrm{v})$,
Flow rate: $0.5 \mathrm{~mL} / \mathrm{min}$, Sample concentration: $20 \mathrm{mg} / \mathrm{mL}$, Sample volume: $5 \mu \mathrm{L}$, Column temperature: $15^{\circ} \mathrm{C}$.

\section{RESULTS AND DISCUSSION}

In formula (1), when q factors are negligible, a full interactions between the stationary phase and the solute TGs must take place by rotating and transforming the shape of the individual TG molecules as depicted in Fig. 1, because the ODS carbon chains in the monomeric stationary phase are not so thick compared to that of the polymeric stationary phase. If we define the chemical potential of the individual TG molecule configurations against the stationary phase as $\Delta \mu_{\mathrm{TGi}}(\mathrm{i}=1 \sim \mathrm{n})$ and retention times of the individual TG molecule configurations as $t_{i}$, the mean chemical potential of TG can be expressed as follows.

$$
\Delta \mu_{\mathrm{TG}}=\left(\mathrm{t}_{1} \Delta \mu_{\mathrm{TG} 1}+\mathrm{t}_{2} \Delta \mu_{\mathrm{TG} 2}+\mathrm{t}_{3} \Delta \mu_{\mathrm{TG} 3}+\cdots+\mathrm{t}_{\mathrm{n}} \Delta \mu_{\mathrm{TGn}}\right) / \sum \mathrm{t}_{\mathrm{i}}
$$

where $\Sigma$ ti designates the total retention times (the retention time of the TG molecular species itself) of the individual TG molecule configurations.

As illustrated in Fig. 2-1, the TG molecules can take various configurations in monomeric column, by rotating and transforming while flowing through the relatively spacy ODS stationary phase chain vacancies compared to the polymeric ODS stationary phase chain vacancies. On the other hand, as illustrated in Fig. 2-2, the TG molecule configurations in polymeric column must be limited to a "long stem direction" because the ODS stationary phase chain vacancies are very limited compared to the monomeric column. And for this reason, it can be considered that positional isomers of TG molecular species must be separated

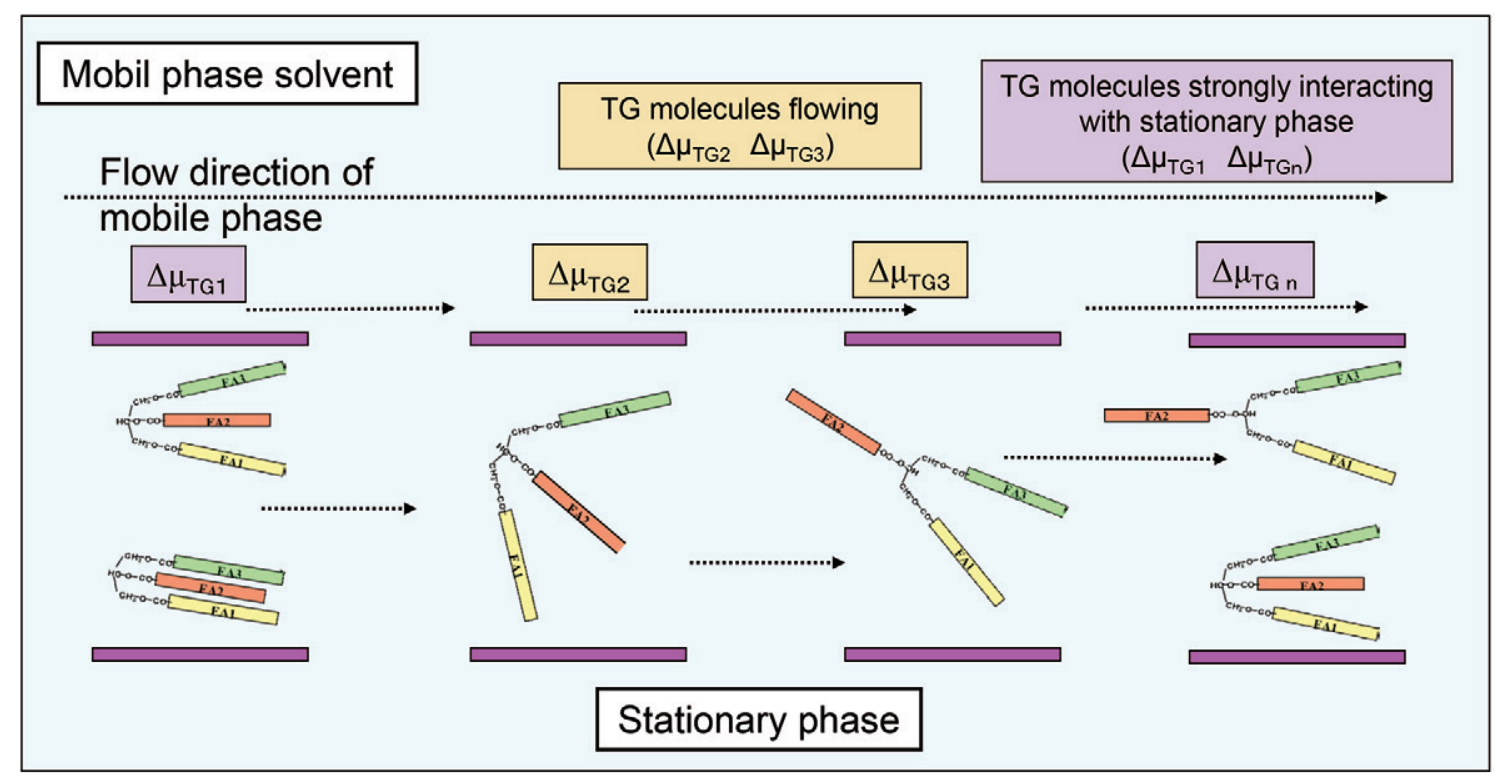

Fig. 1 Imaginary drawing how the TG molecules flow in ODS column. 

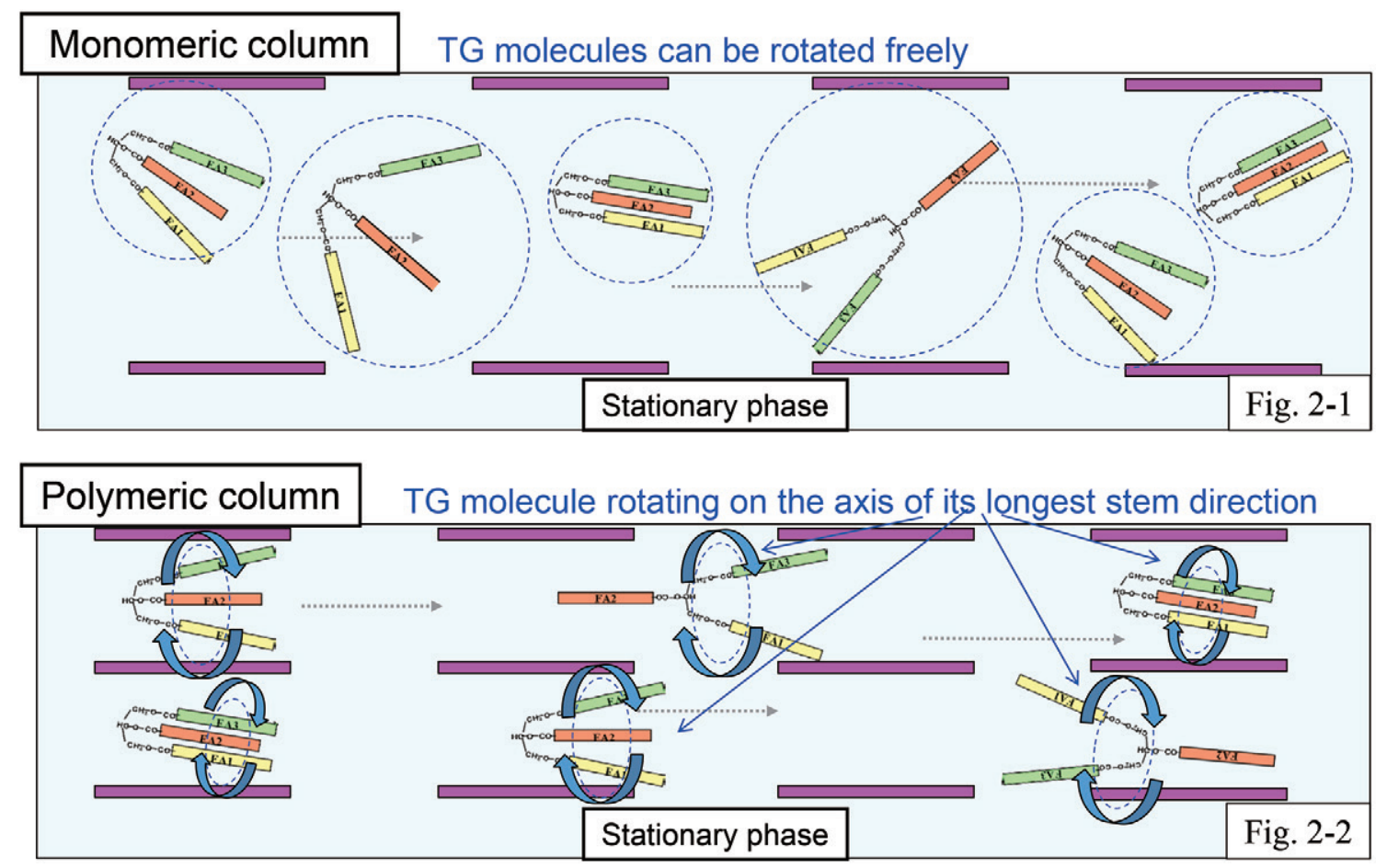

Fig. 2 Comparison between monomeric and polymeric ODS columns of how the TG molecules flow through.

owing to hindrances caused by narrow ODS stationary phase chain vacancies.

\subsection{Interactions between the individual TG positional iso- mers and the stationary phase}

Suppose we express the chemical potential of TG that has $\Delta \mu_{1}>\Delta \mu_{2}>\Delta \mu_{3}$ moieties as $\Delta \mu_{\mathrm{TG}(1,2,3)}$ in the reverse phase partition chromatography,

$$
\begin{aligned}
\Delta \mu_{\mathrm{TG}(1,2,3)}= & \Delta \mu_{1}+\Delta \mu_{2}+\Delta \mu_{3}-\left\{p\left(\Delta \mu_{1}, \Delta \mu_{2}\right)+p\left(\Delta \mu_{2}, \Delta \mu_{3}\right)\right. \\
& \left.+\mathrm{q}\left(\Delta \mu_{1}, \Delta \mu_{3}\right)\right\}
\end{aligned}
$$

On the other hand, the positional isomers $\Delta \mu_{\mathrm{TG}(2,1,3)}$ and $\Delta \mu_{\mathrm{TG}(1,3,2)}$ can be expressed as follows.

$$
\begin{aligned}
\Delta \mu_{\mathrm{TG}(2,1,3)}= & \Delta \mu_{1}+\Delta \mu_{2}+\Delta \mu_{3}-\left\{\mathrm{p}\left(\Delta \mu_{1}, \Delta \mu_{2}\right)+\mathrm{p}\left(\Delta \mu_{1}, \Delta \mu_{3}\right)\right. \\
& \left.+\mathrm{q}\left(\Delta \mu_{2}, \Delta \mu_{3}\right)\right\} \\
\Delta \mu_{\mathrm{TG}(1,3,2)}= & \Delta \mu_{1}+\Delta \mu_{2}+\Delta \mu_{3}-\left\{\mathrm{p}\left(\Delta \mu_{1}, \Delta \mu_{3}\right)+\mathrm{p}\left(\Delta \mu_{2}, \Delta \mu_{3}\right)\right. \\
& \left.+\mathrm{q}\left(\Delta \mu_{1}, \Delta \mu_{2}\right)\right\}
\end{aligned}
$$

If we take the individual subtractions:

$$
\begin{aligned}
& \text { (3) - (4) }=\Delta \mu_{\mathrm{TG}(1,2,3)}-\Delta \mu_{\mathrm{TG}(2,1,3)}=\mathrm{q}\left(\Delta \mu_{2}, \Delta \mu_{3}\right)-\mathrm{q}\left(\Delta \mu_{1}\right. \text {, } \\
& \left.\Delta \mu_{3}\right)-\left\{\mathrm{p}\left(\Delta \mu_{2}, \Delta \mu_{3}\right)-\mathrm{p}\left(\Delta \mu_{1}, \Delta \mu_{3}\right)\right\} \\
& \text { (3) - (5) }=\Delta \mu_{\mathrm{TG}(1,2,3)}-\Delta \mu_{\mathrm{TG}(1,3,2)}=\mathrm{q}\left(\Delta \mu_{1}, \Delta \mu_{2}\right)-\mathrm{q}\left(\Delta \mu_{1}\right. \text {, } \\
& \left.\Delta \mu_{3}\right)-\left\{\mathrm{p}\left(\Delta \mu_{1}, \Delta \mu_{2}\right)-\mathrm{p}\left(\Delta \mu_{1}, \Delta \mu_{3}\right)\right\} \\
& \text { (4) - (5) }=\Delta \mu_{\mathrm{TG}(2,1,3)}-\Delta \mu_{\mathrm{TG}(1,3,2)}=\mathrm{q}\left(\Delta \mu_{1}, \Delta \mu_{2}\right)-\mathrm{q}\left(\Delta \mu_{2}\right. \text {, } \\
& \left.\Delta \mu_{3}\right)-\left\{\mathrm{p}\left(\Delta \mu_{1}, \Delta \mu_{2}\right)-\mathrm{p}\left(\Delta \mu_{2}, \Delta \mu_{3}\right)\right\}
\end{aligned}
$$

The values of formulas (6), (7), (8) correspond to the differences in retention times of each positional isomers. And the terms $\mathrm{p}$ and $\mathrm{q}$ correspond to the interference factors due to differences in binding sn positions of the fatty acid moieties on glycerol backbone. The contribution of $\mathrm{p}$ and $\mathrm{q}$ terms should depend on the chromatographic conditions employed such as mobile phase polarity, molecular size, and kinds of functional groups, system temperature, and flow rate. However, they would not affect on the specific elution order itself on the reverse phase partition chromatography. The most effective factors that affect on terms $\mathrm{p}$ and q must be the carbon chain molecular structures, the density of those carbon chains, and the residual functional groups such as the remaining silanol groups.

\subsection{The size of the effect on interference factors due to differences in binding sn positions of the fatty acid moieties on glycerol backbone}

The size of the effect on interference factors (the interference against interaction between TG molecule and stationary phase) due to differences in binding $s n$ positions of the fatty acid moieties on glycerol backbone, namely the positional isomers, must be determined by the binding positions of the individual fatty acid moieties.

We will now discuss the theoretical aspects of $\mathrm{p}$ and $\mathrm{q}$ in formula (3).

A) Terms $p$ and q rest on the size of the chemical potentials of the bound fatty acid moieties

B) The more the size of the chemical potentials of the 


\section{T. Hirano, K. Yokochi and K. Takahashi}

individual bound fatty acid moieties, terms $\mathrm{p}$ and $\mathrm{q}$ would become large

C) When the sum of the chemical potentials of the bound fatty acid moieties is constant, the smaller the differences in chemical potentials of the individual bound fatty acid moieties, terms $\mathrm{p}$ and $\mathrm{q}$ would become large (it becomes maximum when the difference is 0 )

D) When the sum of the chemical potentials of the bound fatty acid moieties is constant, the more the differences in chemical potentials of the individual bound fatty acid moieties, terms $\mathrm{p}$ and $\mathrm{q}$ would become small (it becomes minimum when the difference is 0)

E) When the sum of the chemical potentials of the bound fatty acid moieties is equal, the size of the interference must become $q>p$.

F) When the chemical potentials of the individual bound fatty acid moieties are small, and when it reaches to a negligible level, $\mathrm{q} \doteqdot \mathrm{p} \Rightarrow 0$. (For example in the case of $\Delta \mu_{1}=\Delta \mu_{2}=\Delta \mu_{3} \doteqdot 0 \quad \Delta \mu_{1}>>\Delta \mu_{2}=\Delta \mu_{3} \doteqdot 0$.

G) From the above $\mathrm{E}$ and $\mathrm{F}$, in accordance with the amount of changes in chemical potentials $(\Delta \mu)$ pertaining to the individual factors in terms $\mathrm{p}$ and $\mathrm{q}$, the following formula should hold.

$$
\partial \mathrm{q} / \partial \Delta \mu>\partial \mathrm{p} / \partial \Delta \mu
$$

Namely, the size of the interference due to the changes in the chemical potentials of the individual bound fatty acid moieties would be $s n-1 \Leftrightarrow s n-3>s n-1 \Leftrightarrow s n-2$ and $s n-2 \Leftrightarrow$ sn-3.

\subsection{Properties of reverse phase monomeric column}

As aforementioned, it is considered that the TG molecules can take various configurations in monomeric column, by rotating and transforming while flowing through the spacy ODS stationary phase chain vacancies.

- They should take configurations that have the minimum free energy.

A first dimensional interactions between the stationary phase and the TG molecules should take place.

In monomeric column, clearances (vacancies) between the ODS stationary phase chains are considered to be more wide compared those of polymeric column, thus allowing TG molecules to rotate and transform to have the minimum free energy while flowing through the spacy ODS stationary phase chain vacancies. For this reason, as illustrated in Fig. 2 upper figure, the effect of the interference due to the changes in the chemical potentials of the individual bound fatty acid moieties is hard to be detected, thus, positional isomers are hard to be separated.
Namely:

$$
\begin{aligned}
\text { (3)- (4) }= & \Delta \mu_{\mathrm{TG}(1,2,3)}-\Delta \mu_{\mathrm{TG}(2,1,3)}=\mathrm{q}\left(\Delta \mu_{2}, \Delta \mu_{3}\right)-\mathrm{q}\left(\Delta \mu_{1},\right. \\
& \left.\Delta \mu_{3}\right)-\left\{\mathrm{p}\left(\Delta \mu_{2}, \Delta \mu_{3}\right)-\mathrm{p}\left(\Delta \mu_{1}, \Delta \mu_{3}\right)\right\} \doteqdot 0 \\
\text { (3)-(5) }= & \Delta \mu_{\mathrm{TG}(1,2,3)}-\Delta \mu_{\mathrm{TG}(1,3,2)}=\mathrm{q}\left(\Delta \mu_{1}, \Delta \mu_{2}\right)-\mathrm{q}\left(\Delta \mu_{1},\right. \\
& \left.\Delta \mu_{3}\right)-\left\{\mathrm{p}\left(\Delta \mu_{1}, \Delta \mu_{2}\right)-\mathrm{p}\left(\Delta \mu_{1}, \Delta \mu_{3}\right)\right\} \doteqdot 0 \\
\text { (4) - (5) }= & \Delta \mu_{\mathrm{TG}(2,1,3)}-\Delta \mu_{\mathrm{TG}(1,3,2)}=\mathrm{q}\left(\Delta \mu_{1}, \Delta \mu_{2}\right)-\mathrm{q}\left(\Delta \mu_{2},\right. \\
& \left.\Delta \mu_{3}\right)-\left\{\mathrm{p}\left(\Delta \mu_{1}, \Delta \mu_{2}\right)-\mathrm{p}\left(\Delta \mu_{2}, \Delta \mu_{3}\right)\right\} \doteq 0
\end{aligned}
$$

As shown in Table 1-1 and 1-2, the resolution of the positional isomers is very poor or not separated. And this coincides with the formulas (10), (11), (12).

\subsection{Properties of polymeric reverse phase column}

As aforementioned, it is considered that the TG molecules cannot take various configurations in polymeric column, by rotating and transforming while flowing between the narrow ODS stationary phase chain vacancies.

- They should take configurations and rotations that are very limited, i.e. limited to only an "long stem direction".

A third dimensional interactions (interactions among the stationary phase molecular groups and the TG molecule) should take place.

In polymeric column, clearances between the ODS stationary phase chains are considered to be very limited compared those of monomeric column, thus limiting the TG molecule transformations and rotations to only a "longest stem direction". For this reason, as illustrated in Fig. 2 lower figure, the effect of the interference occurring in the longest stem direction, must contribute to the separation of TG positional isomers.

\subsection{The longest stem direction in TG molecule}

When TG molecules pass through a very limited clearances between the narrow ODS stationary phase chain vacancies, the individual TG molecules transform and rotate to a longest stem direction in order to minimize the resistance against flowing. In Fig. 3, L (FA1-FA2) corresponds to the "longest stem direction".

\subsection{The interactions between TG molecules and station- ary phase}

3.6.1 Positional isomers with FA1, FA2, FA3 moieties that have $\Delta \mu_{1}>\Delta \mu_{2}>\Delta \mu_{3}$ relations (triacid type)

1) (FA1, FA2, FA3), case of Fig. 4-1

"longest stem direction" corresponds to FA1-FA2

Interactions between the long stem directed molecular form (FA1-FA2) and the stationary phase must be crucial in separating TG positional isomers. Namely, when the interactions between ODS chains and "long stem direction" (FA1-FA2) increases, p' $\left(\Delta \mu_{1}, \Delta \mu_{2}\right)$ must be suppressed. 
Table 1 Separation of TG on monomeric ODS column.

Table 1-1 Separation of triacid TG.

\begin{tabular}{|c|c|c|c|c|c|c|c|}
\hline Total acyl carbon number & TAG moleculer species & Rt & $\ln (\mathrm{Rt})$ & $\triangle \ln (\mathrm{Rt})$ & RRT & $\ln (\mathrm{RRT})$ & $\triangle \ln (\mathrm{Rt})$ \\
\hline \multirow{3}{*}{30} & $\mathrm{C}_{16} \mathrm{C}_{2} \mathrm{C}_{12}$ & 12.78 & 2.55 & & 235.79 & 5.46 & \multirow{3}{*}{$\begin{array}{l}0.00 \\
0.00\end{array}$} \\
\hline & $\mathrm{C}_{16} \mathrm{C}_{12} \mathrm{C}_{2}$ & 12.78 & 2.55 & 0.00 & 235.79 & 5.46 & \\
\hline & $\mathrm{C}_{12} \mathrm{C}_{16} \mathrm{C}_{2}$ & 12.78 & 2.55 & 0.00 & 235.79 & 5.46 & \\
\hline \multirow{3}{*}{36} & $\mathrm{C}_{16} \mathrm{C}_{8} \mathrm{C}_{12}$ & 23.09 & 3.14 & & 433.21 & 6.07 & \\
\hline & $\mathrm{C}_{16} \mathrm{C}_{12} \mathrm{C}_{8}$ & 23.09 & 3.14 & 0.00 & 433.21 & 6.07 & 0.00 \\
\hline & $\mathrm{C}_{12} \mathrm{C}_{16} \mathrm{C}_{8}$ & 23.09 & 3.14 & 0.00 & 433.21 & 6.07 & 0.00 \\
\hline \multirow{2}{*}{40} & $\mathrm{C}_{12} \mathrm{C}_{16} \mathrm{C}_{12}$ & 38.84 & 3.66 & \multirow{2}{*}{0.00} & 698.56 & 6.55 & \multirow{2}{*}{0.00} \\
\hline & $\mathrm{C}_{12} \mathrm{C}_{12} \mathrm{C}_{16}$ & 38.84 & 3.66 & & 698.56 & 6.55 & \\
\hline \multirow{2}{*}{44} & $\mathrm{C}_{16} \mathrm{C}_{12} \mathrm{C}_{16}$ & 61.92 & 4.13 & \multirow{2}{*}{0.00} & 1117.69 & 7.02 & \multirow{2}{*}{0.00} \\
\hline & $\mathrm{C}_{16} \mathrm{C}_{16} \mathrm{C}_{12}$ & 61.92 & 4.13 & & 1117.69 & 7.02 & \\
\hline
\end{tabular}

Table 1-2 Separation of diacid TG.

\begin{tabular}{|c|c|c|c|c|c|c|c|}
\hline Total acyl carbon number & TAG moleculer species & Rt & $\ln (\mathrm{Rt})$ & $\triangle \ln (\mathrm{Rt})$ & RRT & $\underline{\ln \text { (RRT) }}$ & $\triangle \ln (\mathrm{Rt})$ \\
\hline \multirow{2}{*}{30} & $\mathrm{C}_{12} \mathrm{C}_{6} \mathrm{C}_{12}$ & 10.56 & 2.36 & \multirow{2}{*}{0.00} & 213.77 & 5.36 & \multirow{2}{*}{0.00} \\
\hline & $\mathrm{C}_{12} \mathrm{C}_{12} \mathrm{C}_{6}$ & 10.56 & 2.36 & & 213.77 & 5.36 & \\
\hline \multirow{2}{*}{36} & $\mathrm{C}_{16} \mathrm{C}_{4} \mathrm{C}_{16}$ & 21.95 & 3.09 & \multirow{2}{*}{0.00} & 445.23 & 6.10 & \multirow{2}{*}{0.00} \\
\hline & $\mathrm{C}_{16} \mathrm{C}_{16} \mathrm{C}_{4}$ & 21.95 & 3.09 & & 445.23 & 6.10 & \\
\hline \multirow{2}{*}{40} & $\mathrm{C}_{16} \mathrm{C}_{8} \mathrm{C}_{16}$ & 31.85 & 3.46 & \multirow{2}{*}{0.00} & 636.69 & 6.46 & \multirow{2}{*}{0.00} \\
\hline & $\mathrm{C}_{16} \mathrm{C}_{16} \mathrm{C}_{8}$ & 31.85 & 3.46 & & 636.69 & 6.46 & \\
\hline \multirow{2}{*}{40} & $\mathrm{C}_{12} \mathrm{C}_{16} \mathrm{C}_{12}$ & 30.66 & 3.42 & \multirow{2}{*}{0.00} & 614.43 & 6.42 & \multirow{2}{*}{0.00} \\
\hline & $\mathrm{C}_{12} \mathrm{C}_{12} \mathrm{C}_{16}$ & 30.66 & 3.42 & & 614.43 & 6.42 & \\
\hline \multirow{2}{*}{44} & $\mathrm{C}_{16} \mathrm{C}_{12} \mathrm{C}_{16}$ & 47.17 & 3.85 & \multirow{2}{*}{0.00} & 956.80 & 6.86 & \multirow{2}{*}{0.00} \\
\hline & $\mathrm{C}_{16} \mathrm{C}_{16} \mathrm{C}_{12}$ & 47.17 & 3.85 & & 956.80 & 6.86 & \\
\hline
\end{tabular}

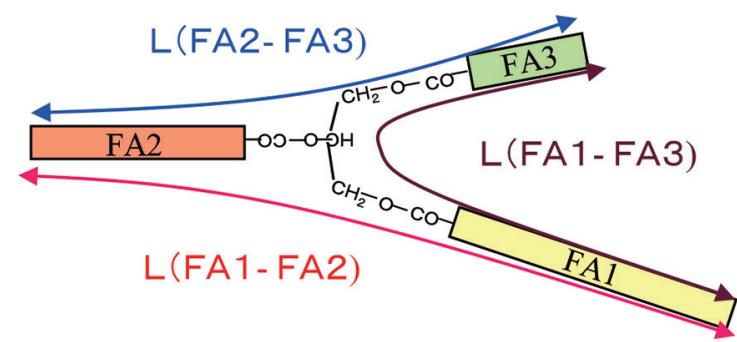

\section{$\mathrm{L}(\mathrm{FA} 1-\mathrm{FA} 2)>\mathrm{L}(\mathrm{FA} 1-\mathrm{FA} 3)>\mathrm{L}(\mathrm{FA} 2-\mathrm{FA} 3)$}

Fig. 3 The longest stem direction in TG molecule.

\section{2) (FA2, FA1, FA3), case of Fig. 4-2}

"longest stem direction" corresponds to FA1-FA2

Interactions between the long stem directed molecular form (FA1-FA2) and the stationary phase must be crucial in separating TG positional isomers. Namely, when the interactions between ODS chains and "long stem direction" (FA1-FA2) increases, $p^{\prime}\left(\Delta \mu_{1}, \Delta \mu_{2}\right)$ must be suppressed.

3) (FA1, FA3, FA2), case of Fig. 4-3

"longest stem direction" corresponds to FA1-FA2

Interactions between the long stem directed molecular form (FA1-FA2) and the stationary phase must be crucial in separating TG positional isomers. Namely, when the interactions between ODS chains and "long stem direction" (FA1-FA2) increases, q' $\left(\Delta \mu_{1}, \Delta \mu_{3}\right)$ must be suppressed.

3.6.2 Positional isomers with FA1, FA2, FA3 moieties that have $\Delta \mu_{1}>\Delta \mu_{2}=\Delta \mu_{3}$ relations (diacid type)

4) (FA1, FA2, FA3), case of Fig. 5-1

"longest stem direction" corresponds to FA1-FA3

Interactions between the long stem directed molecular form (FA1-FA3) and the stationary phase must be crucial in separating TG positional isomers. Namely, when the interactions between ODS chains and "long stem direction" (FA1-FA3) increases, q $\mathrm{q}^{\prime}\left(\Delta \mu_{1}, \Delta \mu_{3}\right)$ must be suppressed.

5) (FA2, FA1, FA3), case of Fig. 5-2

"longest stem direction" corresponds to FA1-FA2 and FA1-FA3

Interactions between the long stem directed molecular forms (FA1-FA2) and (FA1-FA3) and the stationary phase must be crucial in separating TG positional isomers. The interection of the "long stem" must suppress p' $\left(\Delta \mu_{1}, \Delta \mu_{2}\right)$ $\left(=\mathrm{p}^{\prime}\left(\Delta \mu_{1}, \Delta \mu_{3}\right)\right)$.

3.6.3 Positional isomers with FA1, FA2, FA3 moieties that have $\Delta \mu_{1}=\Delta \mu_{2}>\Delta \mu_{3}$ relations (diacid type)

6) (FA1, FA2, FA3), case of Fig. 6-1

"longest stem direction" corresponds to FA1-FA2 

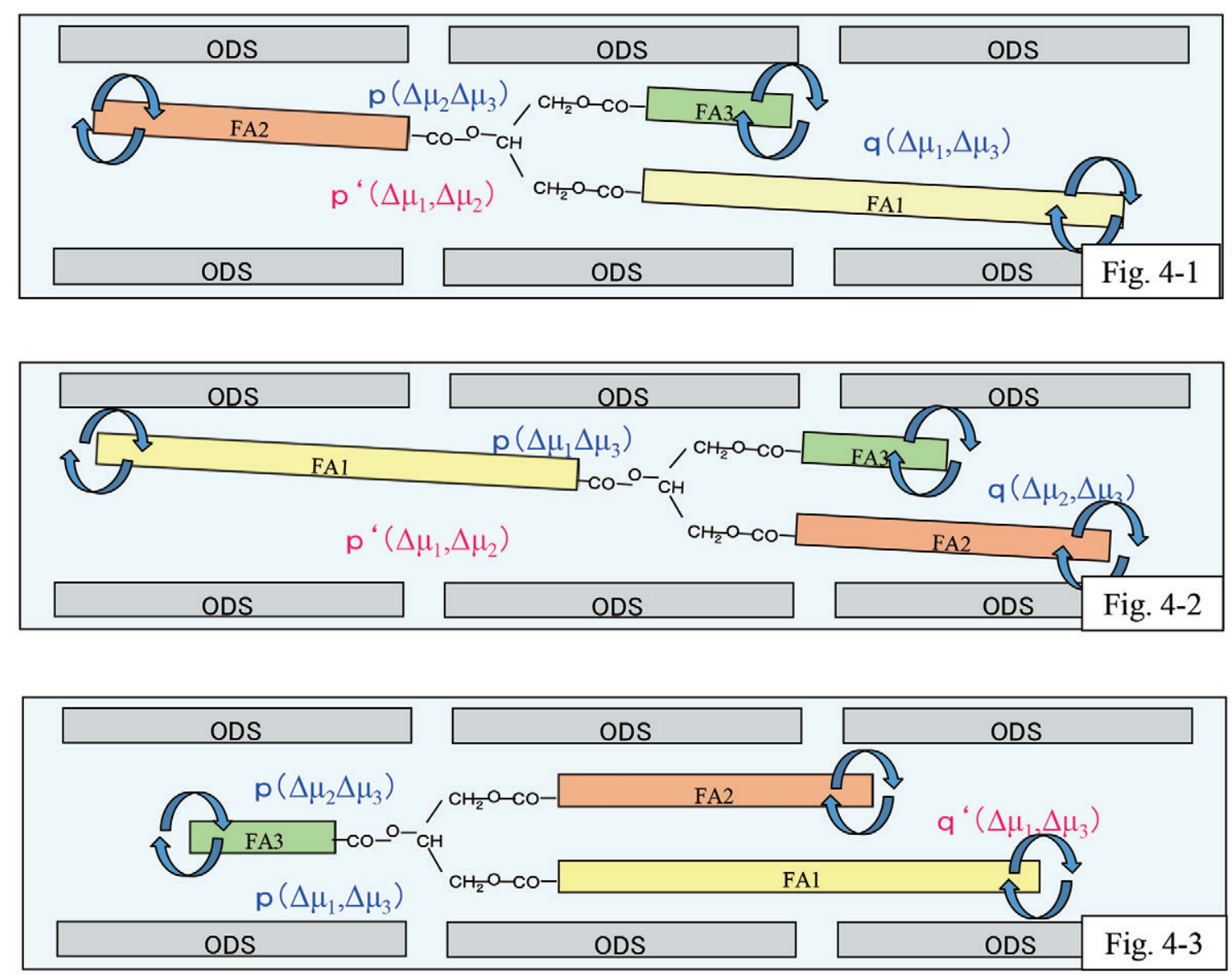

Fig. 4 The interactions between triacid TG molecules and stationary phase.

Interactions between the long stem directed molecular form (FA1-FA2) and the stationary phase must be crucial in separating TG positional isomers. Namely, when the interactions between ODS chains and "long stem direction" (FA1-FA2) increases, p' $\left(\Delta \mu_{1}, \Delta \mu_{2}\right)$ must be suppressed.

7) (FA1, FA3, FA2), case of Fig. 6-2

"longest stem direction" corresponds to FA1-FA2

Interactions between the long stem directed molecular form (FA1-FA2) and the stationary phase must be crucial in separating TG positional isomers. Namely, when the interactions between ODS chains and "long stem direction" (FA1-FA2) increases, q' $\left(\Delta \mu_{1}, \Delta \mu_{2}\right)$ must be suppressed. However, in case of the above 6 ) when the difference in chain lengths between FA2 and FA3 is small and when the number of $\mathrm{CH}_{2}$ groups satisfies the following formula, the lengths of FA1-FA2 and FA1-FA3 becomes same. (this corresponds to a critical chain length)

(Number of $\mathrm{CH}_{2}$ group in FA2)

$-\left\{\left(\right.\right.$ Number of $\mathrm{CH}_{2}$ group in FA3 $\left.)+1\right\}=0$

When (13) $>0$, maximum long stem direction becomes FA1FA2. And when $13<0$, longest stem direction becomes
FA1-FA3. Thus the longest stem direction changes at the critical chain length. And this means that the linearity of the interaction becomes invalid at this critical chain length point. This explains why there is a difference in separation of positional isomers between the triacid TG molecular species and the diacid TG molecular species. We should say that there must be a state change in interaction between the TG molecule and the stationary phase at the critical acyl carbon length.

\subsection{Theoretical aspects of the separation of TG positional isomers on polymeric reverse phase column}

Rest on the above consideration, we will now discuss the theoretical aspects of the separation of TG positional isomers on polymeric reverse phase HPLC.

In polymeric column, clearances between the ODS stationary phase chains are considered to be very limited, namely the ODS chains are highly thick, compared those of monomeric column, thus limiting the TG molecule transformations and rotations only to a "longest stem direction" for passing through the clearances. This resistance should contribute to the separations of TG positional isomers.

By designating the interference factors as $\mathrm{p}\left(\Delta \mu_{1}, \Delta \mu_{2}\right), \mathrm{p}$ 

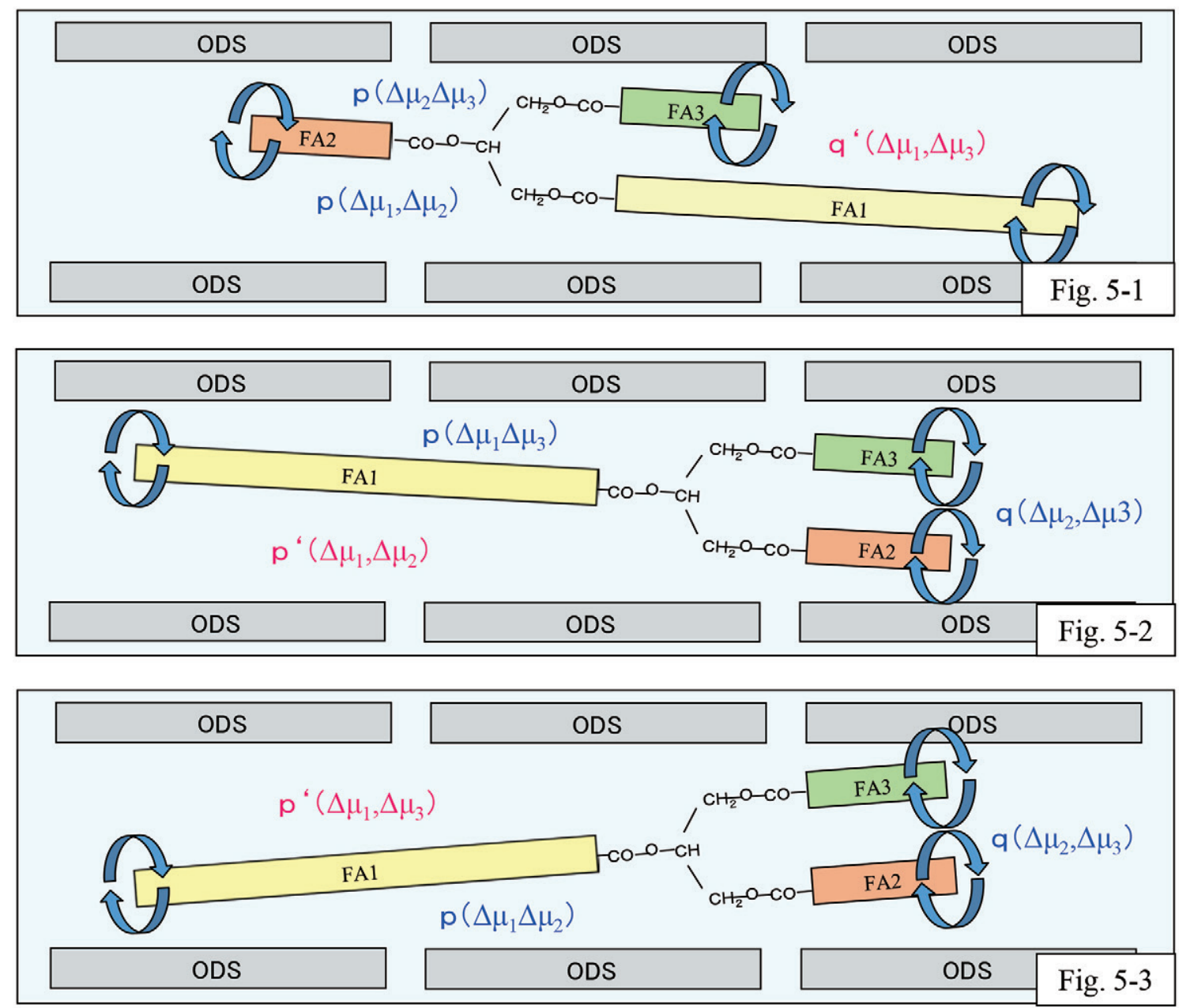

Fig. 5 The interactions between diacid TG molecules and stationary phase.

Positional isomers with FA1, FA2, FA3 moieties that have $\Delta \mu_{1}>\Delta \mu_{2}=\Delta \mu_{3}$ relations.

$\left(\Delta \mu_{2}, \Delta \mu_{3}\right)$, and $\mathrm{q}\left(\Delta \mu_{1}, \Delta \mu_{3}\right)$ between $s n-1 \Leftrightarrow s n-2, s n-2 \Leftrightarrow s n-$ 3 , and $s n-1 \Leftrightarrow s n-3$ in TG which have FA1 $\left(\Delta \mu_{1}\right), \operatorname{FA} 2\left(\Delta \mu_{2}\right)$, and FA3 $\left(\Delta \mu_{3}\right)$ moieties, and express the suppression against interference factors due to the longest stem directed molecular form as p' and q', the chemical potentials of the individual TG positional isomers can be expressed as follows.

3.7.1 Positional isomers with FA1, FA2, FA3 moieties that have $\Delta \mu_{1}>\Delta \mu_{2}>\Delta \mu_{3}$ relations (triacid type)

1) (FA1, FA2, FA3) (Details in "longest stem direction" and the influenced p' and q' are depicted in 3.6.1.)

$\Delta \mu_{\mathrm{TG}(1,2,3)}=\Delta \mu_{1}+\Delta \mu_{2}+\Delta \mu_{3}-\left\{p^{\prime}\left(\Delta \mu_{1}, \Delta \mu_{2}\right)+\mathrm{p}\left(\Delta \mu_{2}, \Delta \mu_{3}\right)\right.$ $\left.+\mathrm{q}\left(\Delta \mu_{1}, \Delta \mu_{3}\right)\right\}$

2) (FA2, FA1, FA3) (Details in "longest stem direction" and the influenced p' and q' are depicted in 3.6.1.)

$\Delta \mu_{\mathrm{TG}(2,1,3)}=\Delta \mu_{1}+\Delta \mu_{2}+\Delta \mu_{3}-\left\{\mathrm{p}^{\prime}\left(\Delta \mu_{1}, \Delta \mu_{2}\right)+\mathrm{p}\left(\Delta \mu_{1}, \Delta \mu_{3}\right)\right.$ $\left.+\mathrm{q}\left(\Delta \mu_{2}, \Delta \mu_{3}\right)\right\}$

3) (FA1, FA3, FA2) (Details in "longest stem direction" and the influenced p' and q' are depicted in 3.6.1.)

$\Delta \mu_{\mathrm{TG}(1,3,2)}=\Delta \mu_{1}+\Delta \mu_{2}+\Delta \mu_{3}-\left\{\mathrm{p}\left(\Delta \mu_{1}, \Delta \mu_{3}\right)+\mathrm{p}\left(\Delta \mu_{2}, \Delta \mu_{3}\right)\right.$
$\left.+\mathrm{q}^{\prime}\left(\Delta \mu_{1}, \Delta \mu_{2}\right)\right\}$

(16)

If we take the individual subtractions:

(14) - (15) $=\Delta \mu_{\mathrm{TG}(1,2,3)}-\Delta \mu_{\mathrm{TG}(2,1,3)}=\mathrm{q}\left(\Delta \mu_{2}, \Delta \mu_{3}\right)-\mathrm{q}\left(\Delta \mu_{1}\right.$, $\left.\Delta \mu_{3}\right)-\left\{\mathrm{p}\left(\Delta \mu_{2}, \Delta \mu_{3}\right)-\mathrm{p}\left(\Delta \mu_{1}, \Delta \mu_{3}\right)\right\}$

(14) - (16) $=\Delta \mu_{\mathrm{TG}(1,2,3)}-\Delta \mu_{\mathrm{TG}(1,3,2)}=\mathrm{q}^{\prime}\left(\Delta \mu_{1}, \Delta \mu_{2}\right)-\mathrm{q}\left(\Delta \mu_{1}\right.$, $\left.\Delta \mu_{3}\right)-\left\{p^{\prime}\left(\Delta \mu_{1}, \Delta \mu_{2}\right)-\mathrm{p}\left(\Delta \mu_{1}, \Delta \mu_{3}\right)\right\}$

(15) $-(16)=\Delta \mu_{\mathrm{TG}(2,1,3)}-\Delta \mu_{\mathrm{TG}(1,3,2)}=\mathrm{q}^{\prime}\left(\Delta \mu_{1}, \Delta \mu_{2}\right)-\mathrm{q}\left(\Delta \mu_{2}\right.$, $\left.\Delta \mu_{3}\right)-\left\{p^{\prime}\left(\Delta \mu_{1}, \Delta \mu_{2}\right)-\mathrm{p}\left(\Delta \mu_{2}, \Delta \mu_{3}\right)\right\}$

From the data in the frame of Table 2, plus or minus signs for the individual subtractions above are as follows.

(14) - (15) $=\Delta \mu_{\mathrm{TG}(1,2,3)}-\Delta \mu_{\mathrm{TG}(2,1,3)}=\mathrm{q}\left(\Delta \mu_{2}, \Delta \mu_{3}\right)-\mathrm{q}\left(\Delta \mu_{1}\right.$, $\left.\Delta \mu_{3}\right)-\left\{p\left(\Delta \mu_{2}, \Delta \mu_{3}\right)-p\left(\Delta \mu_{1}, \Delta \mu_{3}\right)\right\}<0$

(14) - (16) $=\Delta \mu_{\mathrm{TG}(1,2,3)}-\Delta \mu_{\mathrm{TG}(1,3,2)}=\mathrm{q}^{\prime}\left(\Delta \mu_{1}, \Delta \mu_{2}\right)-\mathrm{q}\left(\Delta \mu_{1}\right.$, $\left.\Delta \mu_{3}\right)-\left\{p^{\prime}\left(\Delta \mu_{1}, \Delta \mu_{2}\right)-p\left(\Delta \mu_{1}, \Delta \mu_{3}\right)\right\}>0$

(15) - (16) $=\Delta \mu_{\mathrm{TG}(2,1,3)}-\Delta \mu_{\mathrm{TG}(1,3,2)}=\mathrm{q}^{\prime}\left(\Delta \mu_{1}, \Delta \mu_{2}\right)-\mathrm{q}\left(\Delta \mu_{2}\right.$, $\left.\Delta \mu_{3}\right)-\left\{\mathrm{p}^{\prime}\left(\Delta \mu_{1}, \Delta \mu_{2}\right)-\mathrm{p}\left(\Delta \mu_{2}, \Delta \mu_{3}\right)\right\}>0$ 

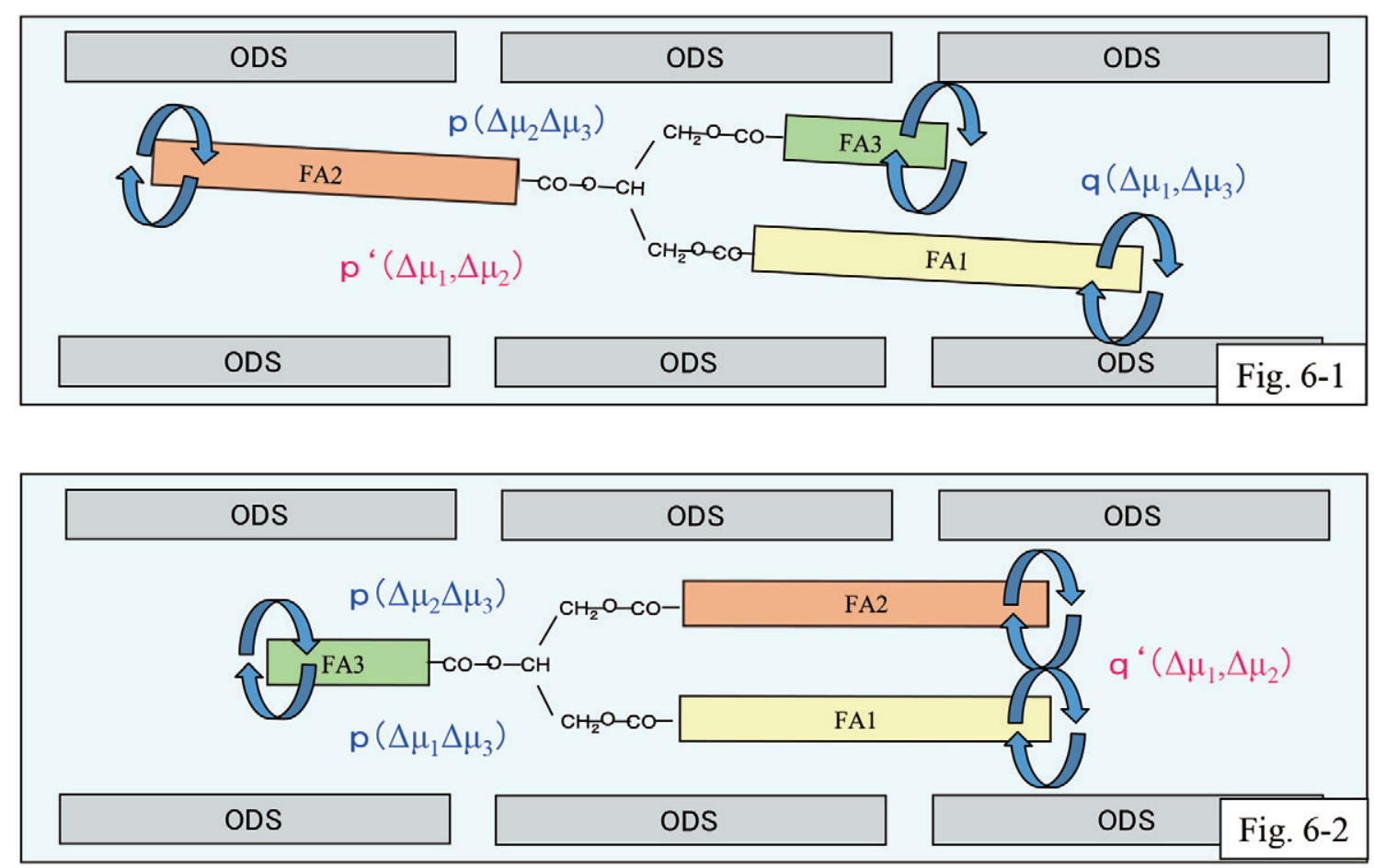

Fig. 6 The interactions between diacid TG molecules and stationary phase.

Positional isomers with FA1, FA2, FA3 moieties that have $\Delta \mu_{1}>\Delta \mu_{2}=\Delta \mu_{3}$ relations.

Table 2 Separation of TG on polymeric ODS column.

\begin{tabular}{c} 
Total acyl carbon number \\
\hline \hline
\end{tabular}

Inside the frame shows the evidence for formula (20, (21), (22), and the dotted frame shows the evidence that reversal phenomenon on elution order occurs when the longest stem direction changes.

3.7.2 Positional isomers with FA1, FA2, FA3 moieties that have $\Delta \mu_{1}>\Delta \mu_{2}=\Delta \mu_{3}$ relations (diacid type)

4) (FA1, FA2, FA3) (Details in "longest stem direction" and the influenced p' and q' are depicted in 3.6.2.)

$\begin{aligned} \Delta \mu_{\mathrm{TG}(1,2,3)}= & \Delta \mu_{1}+\Delta \mu_{2}+\Delta \mu_{3}-\left\{\mathrm{p}\left(\Delta \mu_{1}, \Delta \mu_{2}\right)+\mathrm{p}\left(\Delta \mu_{2}, \Delta \mu_{3}\right)\right. \\ & \left.+\mathrm{q}\left(\Delta \mu_{1}, \Delta \mu_{3}\right)\right\}\end{aligned}$

5) (FA2, FA1, FA3) (Details in "longest stem direction" and the influenced p' and q' are depicted in 3.6.2.)

$\Delta \mu_{\mathrm{TG}(2,1,3)}=\Delta \mu_{1}+\Delta \mu_{2}+\Delta \mu_{3}-\left\{\mathrm{p}\left(\Delta \mu_{1}, \Delta \mu_{2}\right)+\mathrm{p}\left(\Delta \mu_{1}, \Delta \mu_{3}\right)\right.$

$$
\left.+\mathrm{q}\left(\Delta \mu_{2}, \Delta \mu_{3}\right)\right\}
$$

By taking the subtraction:

(23) - (24) $=\Delta \mu_{\mathrm{TG}(1,2,3)}-\Delta \mu_{\mathrm{TG}(2,1,3)}=\mathrm{q}\left(\Delta \mu_{2}, \Delta \mu_{3}\right)-\mathrm{q}^{\prime}\left(\Delta \mu_{1}\right.$,

$$
\left.\Delta \mu_{3}\right)-\left\{\mathrm{p}\left(\Delta \mu_{2}, \Delta \mu_{3}\right)-\mathrm{p}\left(\Delta \mu_{1}, \Delta \mu_{3}\right)\right\}>0
$$

Refer to inside the frame in Table 3 for the evidence.

3.7.3 Positional isomers with FA1, FA2, FA3 moieties that have $\Delta \mu_{1}=\Delta \mu_{2}>\Delta \mu_{3}$ relations (diacid type)

6) (FA1, FA2, FA3) (Details in "longest stem direction" and the influenced p' and q' are depicted in 3.6.3.)

$\Delta \mu_{\mathrm{TG}(1,2,3)}=\Delta \mu_{1}+\Delta \mu_{2}+\Delta \mu_{3}-\left\{\mathrm{p}^{\prime}\left(\Delta \mu_{1}, \Delta \mu_{2}\right)+\mathrm{p}\left(\Delta \mu_{2}, \Delta \mu_{3}\right)\right.$

7) (FA1, FA3 FA2) (Details in "longest stem direction" and the influenced p' and q' are depicted in 3.6.3.)

$\Delta \mu_{\mathrm{TG}(1,3,2)}=\Delta \mu_{1}+\Delta \mu_{2}+\Delta \mu_{3}-\left\{\mathrm{p}\left(\Delta \mu_{1}, \Delta \mu_{3}\right)+\mathrm{p}\left(\Delta \mu_{2}, \Delta \mu_{3}\right)\right.$ $\left.+\mathrm{q}^{\prime}\left(\Delta \mu_{1}, \Delta \mu_{2}\right)\right\}$ 
Table 3 Separation of diacid TG positional isomers on polymeric ODS column.

\begin{tabular}{|c|c|c|c|c|c|c|c|}
\hline Total acyl carbon number & TAG moleculer species & Rt & $\ln (\mathrm{Rt})$ & $\triangle \ln (\mathrm{Rt})$ & RRT & $\ln (\mathrm{RRT})$ & $\triangle \ln (\mathrm{Rt})$ \\
\hline 30 & $\begin{array}{l}\mathrm{C}_{12} \mathrm{C}_{6} \mathrm{C}_{12} \\
\mathrm{C}_{12} \mathrm{C}_{12} \mathrm{C}_{6}\end{array}$ & $\begin{array}{l}9.73 \\
9.73\end{array}$ & $\begin{array}{l}2.28 \\
2.28\end{array}$ & 0.00 & $\begin{array}{l}240.25 \\
240.25\end{array}$ & $\begin{array}{l}5.48 \\
5.48\end{array}$ & 0.00 \\
\hline 36 & $\begin{array}{l}\mathrm{C}_{16} \mathrm{C}_{4} \mathrm{C}_{16} \\
\mathrm{C}_{16} \mathrm{C}_{16} \mathrm{C}_{4}\end{array}$ & $\begin{array}{l}33.10 \\
39.93\end{array}$ & $\begin{array}{l}3.50 \\
3.69\end{array}$ & 0.19 & $\begin{array}{l}819.31 \\
988.37\end{array}$ & $\begin{array}{l}6.71 \\
6.90\end{array}$ & 0.19 \\
\hline 40 & $\begin{array}{l}\mathrm{C}_{16} \mathrm{C}_{8} \mathrm{C}_{16} \\
\mathrm{C}_{16} \mathrm{C}_{16} \mathrm{C}_{8}\end{array}$ & $\begin{array}{l}42.55 \\
47.14\end{array}$ & $\begin{array}{l}3.75 \\
3.85\end{array}$ & 0.10 & $\begin{array}{l}1066.42 \\
1181.45\end{array}$ & $\begin{array}{l}6.97 \\
7.07 \\
\cdots . .1\end{array}$ & 0.10 \\
\hline 40 & $\begin{array}{l}\mathrm{C}_{12} \mathrm{C}_{16} \mathrm{C}_{12} \\
\mathrm{C}_{12} \mathrm{C}_{12} \mathrm{C}_{16}\end{array}$ & $\begin{array}{l}42.62 \\
43.79 \\
\end{array}$ & $\begin{array}{l}3.75 \\
3.78 \\
\end{array}$ & 0.03 & $\begin{array}{l}1009.95 \\
1037.68 \\
\end{array}$ & $\begin{array}{l}6.92 \\
6.95 \\
\end{array}$ & 0.03 \\
\hline 44 & $\begin{array}{l}\mathrm{C}_{16} \mathrm{C}_{12} \mathrm{C}_{16} \\
\mathrm{C}_{16} \mathrm{C}_{16} \mathrm{C}_{12}\end{array}$ & $\begin{array}{r}76.42 \\
78.06 \\
\end{array}$ & $\begin{array}{l}4.34 \\
4.36 \\
\end{array}$ & 0.02 & $\begin{array}{r}1929.8 \\
1971.21\end{array}$ & $\begin{array}{l}7.57 \\
7.59 \\
\end{array}$ & 0.02 \\
\hline
\end{tabular}

Inside the frame shows the evidence for formula (25), and the dotted frame shows the evidence for formula (28).

$\begin{aligned} \text { (26) - (27) }= & \Delta \mu_{\mathrm{TG}(1,2,3)}-\Delta \mu_{\mathrm{TG}(1,3,2)}=\mathrm{q}^{\prime}\left(\Delta \mu_{1}, \Delta \mu_{2}\right)-\mathrm{q}\left(\Delta \mu_{1},\right. \\ & \left.\Delta \mu_{3}\right)-\left\{\mathrm{p}^{\prime}\left(\Delta \mu_{1}, \Delta \mu_{2}\right)-\mathrm{p}\left(\Delta \mu_{1}, \Delta \mu_{3}\right)\right\}>0\end{aligned}$

Refer to inside the frame in Table 3 for the evidence.

\section{SUMMARY}

Rest on the data, we can sum up the theoretical aspect of the separation of TG positional isomers on polymeric reverse phase column as follows.

1) The separation of TG positional isomers on reverse phase HPLC depends on the effect of the interference occurring between the fatty acid moieties.

2) The ODS stationary phase chains are not thick in monomeric reverse phase HPLC column compared to that of polymeric, thus only a first dimensional interactions between the stationary phase and the TG molecules should take place. And for this reason, TG positional isomers are hard to be separated.

3) In contrast, ODS stationary phase chains are thick in polymeric reverse phase HPLC column compared to that of monomeric, thus third dimensional interactions between the stationary phase and the TG molecules should take place. And for this reason, TG positional isomers can be separated.

4) The size of suppression against interference factors on interaction between stationary phase and TG molecules depends on the binding sn position of TG acyl moieties. And if we express $s n-1 \Leftrightarrow s n-2$ and $s n$ $2 \Leftrightarrow s n-3$ as "p", $s n-1 \Leftrightarrow s n-3$ as "q" when the acyl moiety combination is the same, $q>p>0$ should hold.

5) The larger the chemical potential of the acyl moieties, the larger $\mathrm{p}$ and $\mathrm{q}$ becomes. And the rate of change of them is $\partial \mathrm{q} / \partial \Delta \mu>\partial \mathrm{p} / \partial \Delta \mu>0$

6) When TG molecules pass through a polymeric column, TG molecules transform themselves to get a minimum resistance shape for passing.
7) When the longest stem direction of the TG molecule is parallel to the stationary phase, it must be the most stable TG status. And in polymeric column, interference occurring between the fatty acid moieties that affect the interaction between TG molecule and stationary phase must be responsible for the separation of TG isomers.

8) The longest stem direction of the TG molecule corresponds to the acyl moiety pair which gives the largest chemical potential.

9) The longest stem direction of the TG moiety pairs tends to position parallel to the stationary phase as possible. And as a result, interference factor occurring between the fatty acid moieties that affect the interaction between TG molecule and stationary phase must be suppressed. If we express this factor as $\mathrm{p}$ and $\mathrm{q}, \mathrm{p}^{\prime}<\mathrm{p}$ and $\mathrm{q}^{\prime}<\mathrm{q}$ are considered to be hold. (When acyl moiety combinations are the same.)

10) In another word, all other TG moiety pairs with shorter stem directions which occur interference between those moieties should affect the interaction more between TG molecule and stationary phase.

11) The longest stem direction of the TG moiety pairs depends on the binding position. If we stand for chemical potential of the longest stem direction of the TG moiety pairs as numbers of $\mathrm{CH} 2$ groups for convenience's sake, the number of $\mathrm{CH} 2$ groups in FA2 and FA3 moieties that satisfy FA2 $-(\mathrm{FA} 3+1)=$ 0 when binding to $s n-2$ and $s n-3$ position, the longest stem direction of the TG moiety pairs can be expressed as $\mathrm{L}(\mathrm{FA} 1-\mathrm{FA} 2)=\mathrm{L}(\mathrm{FA} 1-\mathrm{FA} 3)$. (This corresponds to the critical chain length)

12) From the definition of critical chain length, when $\mathrm{FA} 2>\mathrm{FA} 3+1$, the longest stem direction of the TG moiety pairs corresponds to FA1 - FA2, while when $\mathrm{FA} 2<\mathrm{FA} 3+1$, the longest stem direction of the TG moiety pairs corresponds to FA1 - FA3. 


\section{T. Hirano, K. Yokochi and K. Takahashi}

13) As depicted in 3.6.3, the effect of the interference occurring between the fatty acid moieties which have the longest stem direction must be suppressed. For this reason, the effect of the interference occurring between the fatty acid moieties at the critical acyl carbon length changes drastically. (effects of $\mathrm{p} \rightarrow \mathrm{p}^{\prime}$ and $\mathrm{q} \rightarrow \mathrm{q}^{\prime}$ in 3.6.3)

14) The reason why the chromatographic behavior seems different between the diacid (formula (25) and triacid (formula (20) TGs at least in part, namely partially changing the elution order of the positional isomers, it can be explained by resting on the above 11), 12) and 13). For example, in formula (25), due to the effect of interference between the TG moieties with longest stem direction designated as p' and q', the +- sign changes.

15) However in diacid TG when there is a $\Delta \mu_{1}=\Delta \mu_{2}>$ $\Delta \mu_{3}$ relation in the composed fatty acid moieties, there is no specific change in the longest stem direction depending on the binding sn position. In this case, the chromatographic behavior of the positional isomers become the same with triacid TG. And formula (22) becomes equal to (28). (If we substitute $\Delta \mu_{1}$ $=\Delta \mu_{2}$ into (28), it gives equal value.)

16) We can develop the above consideration by examining the obtained data as follows:

A) When the longest stem direction is short enough to rotate and transform freely in polymeric column, the positional isomers cannot be well separated. And the individual retention times are also short not allowing the positional isomers to be separated. (From the data in Figs. 8 to 10)

B) When the longest stem direction is long enough to restrict the rotation and transformation in polymeric column, the effect of the interference occurring between the fatty acid moieties becomes prominent. Thus, it becomes possible to discriminate the positional isomers on polymeric column HPLC. (From the data inside the frames in Figs. 8 to 10)

C) In the above B), in the longest stem direction, the effect of the interference occurring between the fatty acid moieties is restricted. And as a result, the rate of change in chemical potential in accordance with the number of atomic groups becomes large. (From the data in Figs. 7 to 10)

D) When TG is shifted from triacid form to diacid form, the longest stem direction changes. And as a result, reversal phenomenon in elution order occurs. (From the data inside the dotted frame in Table 2 and also Figs. 7 to 10)

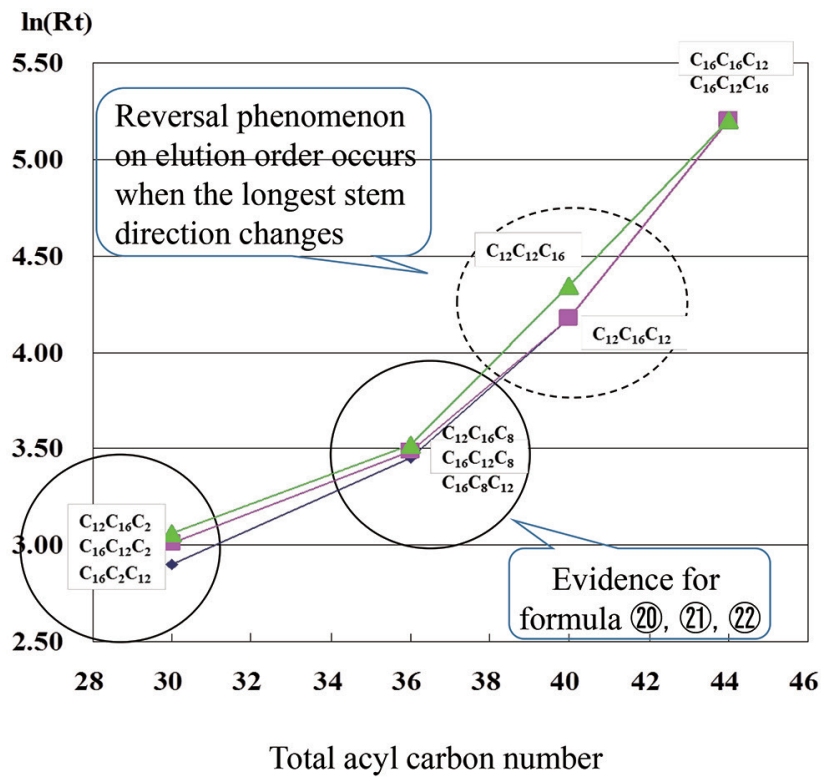

Fig. 7 Reversal phenomenon in elution order observed when TG is shifted from triacid form to diacid form.

Refer to Table 2.

$\triangle$ : ABC type; $\square$ : BAC type; $\diamond$ : BCA type

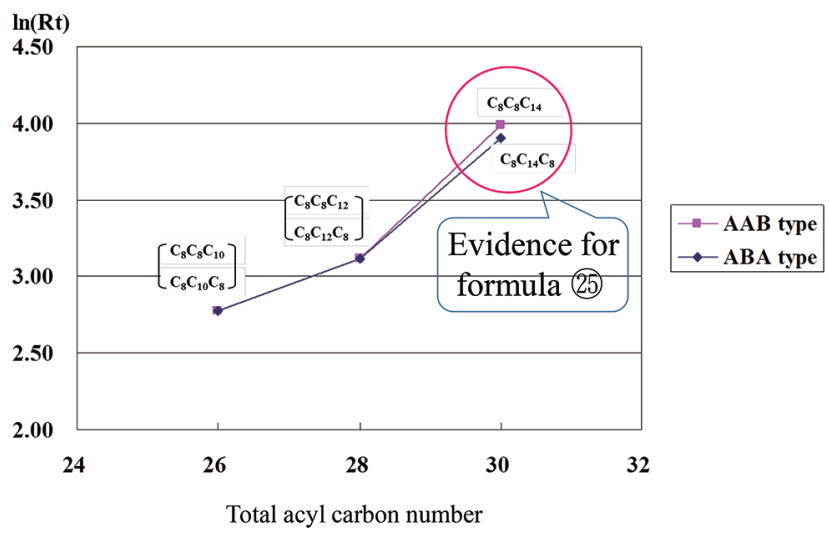

Fig. 8 The rate of change in chemical potential in accordance with the number of atomic groups. $\triangle$ : AAB type; $\square$ : ABA type

\section{CONCLUSION}

We can sum up by saying:

In polymeric column, thickness of the ODS chain is high compared to monomeric column. And for this reason, clearances between the ODS stationary phase chains are considered to be very limited compared those of monomeric column, thus limiting the TG molecule transformations and rotations to only a "longest stem direction" which gives the smallest resistance in passing through.

When the longest stem direction of the TG molecule is parallel to the stationary phase, namely the when 


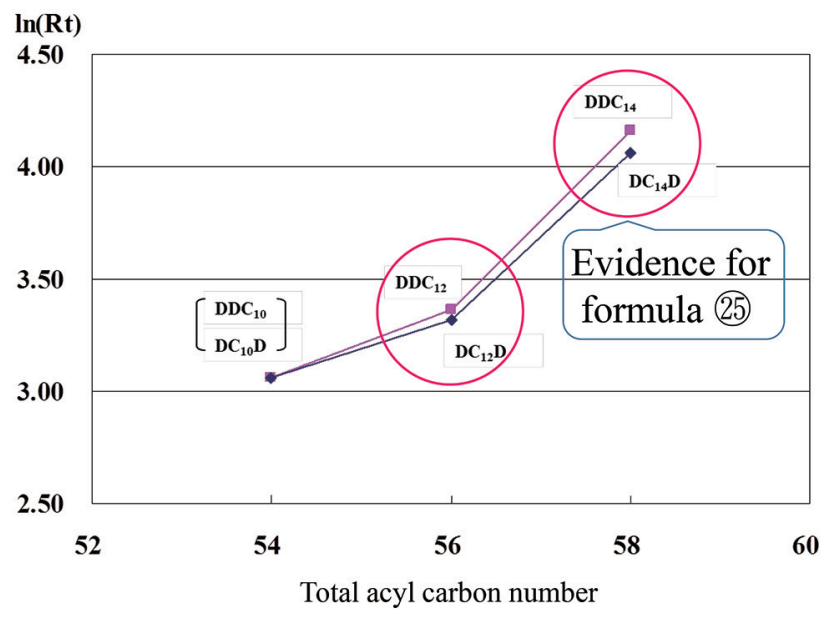

Fig. 9 Relationship between the retention time of molecular species of diacid saturated TG versus total acyl carbon number on polymeric ODS HPLC. Data of N. Gotoh et $a .^{3)}$ were used.

$\triangle$ : AAB type; $\square$ : ABA type

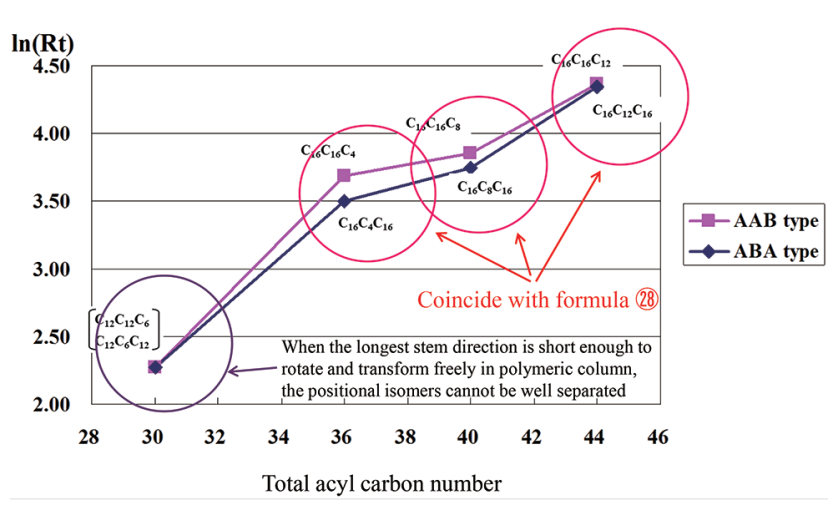

Fig. 10 Relationship between the retention time of molecular species of diacid saturated TG versus total acyl carbon number on polymeric ODS HPLC.

$\triangle$ : AAB type; $\square$ : ABA type

resistance of flow is minimum, that must be the most stable TG status.
The longest stem direction of the TG molecule must be the crucial factor for the interaction between the stationary phase. (specified condition for the interaction between the stationary phase and the TG molecule must be determined)

Specified condition refers to rotation of the TG molecule rotating on the axis of its longest stem direction. And under this condition, interference occurring between the fatty acid moieties must be the main contributing factor for positional isomer separation. i.e. the $\mathrm{p}$ term and $\mathrm{q}$ term so far denoted.

Interference factor occurring between the fatty acid moieties that affect the interaction between TG molecule and stationary phase is suppressed for the longest stem directed TG acyl moiety combination. (This is because the longest stem directed TG acyl moiety combination must be stable in status when placing parallel to the stationary phase molecules.

The above aspects tell why they are not consistent with the addition theorem of A.J.P. Martin ${ }^{2}$.

\section{ACKNOWLEDGMENT}

Thanks are due to Mr. Hoyou Mizobe and Kenji Ichioka of TSUKISHIMA FOODS INDUSTRY CO., LTD. for their generous authentic TG standard gifts.

\section{References}

1) Yokochi, K. Master's thesis, Hokkaido University. Hakodate, in Japanese, (2013).

2) Martin, A.J.P. Biochem. Soc. Symposia, (Cambridge, England), 3, 4-20 (1950).

3) Gotoh, N.; Matsumoto, Y.; Yuji, H.; Nagai, T.; Mizobe, H.; Ichioka, K.; Kuroda, I.; Noguchi, N.; Wada, S. J. Oleo Sci. 59, 71-79(2010). 